\title{
UNIVERSITYOF BIRMINGHAM

\section{Multiplex ligation-dependent probe amplification (MLPA) analysis is an effective tool for the detection of novel intragenic PLA2G6 mutations: Implications for molecular diagnosis}

Crompton, D; Rehal, PK; MacPherson, L; Foster, K; Lunt, P; Hughes, I; Brady, AF; Pike, MG; De Gressi, S; Morgan, Neil; Hardy, C; Smith, M; MacDonald, Fiona; Maher, Eamonn; Kurian, Manju

DOI:

10.1016/j.ymgme.2010.02.009

Citation for published version (Harvard):

Crompton, D, Rehal, PK, MacPherson, L, Foster, K, Lunt, P, Hughes, I, Brady, AF, Pike, MG, De Gressi, S, Morgan, N, Hardy, C, Smith, M, MacDonald, F, Maher, E \& Kurian, M 2010, 'Multiplex ligation-dependent probe amplification (MLPA) analysis is an effective tool for the detection of novel intragenic PLA2G6 mutations: Implications for molecular diagnosis', Molecular Genetics and Metabolism, vol. 100, no. 2, pp. 207-212. https://doi.org/10.1016/j.ymgme.2010.02.009

Link to publication on Research at Birmingham portal

\section{General rights}

Unless a licence is specified above, all rights (including copyright and moral rights) in this document are retained by the authors and/or the copyright holders. The express permission of the copyright holder must be obtained for any use of this material other than for purposes permitted by law.

- Users may freely distribute the URL that is used to identify this publication.

- Users may download and/or print one copy of the publication from the University of Birmingham research portal for the purpose of private study or non-commercial research.

- User may use extracts from the document in line with the concept of 'fair dealing' under the Copyright, Designs and Patents Act 1988 (?)

- Users may not further distribute the material nor use it for the purposes of commercial gain.

Where a licence is displayed above, please note the terms and conditions of the licence govern your use of this document.

When citing, please reference the published version.

\section{Take down policy}

While the University of Birmingham exercises care and attention in making items available there are rare occasions when an item has been uploaded in error or has been deemed to be commercially or otherwise sensitive.

If you believe that this is the case for this document, please contact UBIRA@lists.bham.ac.uk providing details and we will remove access to the work immediately and investigate.

Download date: 26. Apr. 2023 
Brief Communication

\title{
Multiplex ligation-dependent probe amplification (MLPA) analysis is an effective tool for the detection of novel intragenic PLA2G6 mutations: Implications for molecular diagnosis
}

\author{
Danielle Crompton ${ }^{\mathrm{a}}$, Pauline K. Rehal ${ }^{\mathrm{a}}$, Lesley MacPherson ${ }^{\mathrm{b}}$, Katharine Foster ${ }^{\mathrm{b}}$, Peter Lunt $^{\mathrm{c}}$, \\ Imelda Hughes ${ }^{\mathrm{d}}$, Angela F. Brady ${ }^{\mathrm{e}}$, Michael G. Pike ${ }^{\mathrm{f}}$, Susanna De Gressi ${ }^{\mathrm{g}}$, Neil V. Morgan ${ }^{\mathrm{h}}$, Carol Hardy ${ }^{\mathrm{a}}$, \\ Matthew Smith ${ }^{a}$, Fiona MacDonald ${ }^{\mathrm{a}}$, Eamonn R. Maher ${ }^{\mathrm{a}, \mathrm{h}}$, Manju A. Kurian ${ }^{\mathrm{h}, \mathrm{i}, *}$ \\ a West Midlands Regional Genetic Service, Birmingham Women's Hospital, Metchley Park Lane, Edgbaston, Birmingham B15 2 TG, UK \\ ${ }^{\mathrm{b}}$ Department of Radiology, Birmingham Children's Hospital, Steelhouse Lane, Birmingham B4 6NH, UK \\ ${ }^{\mathrm{c}}$ Department of Clinical Genetics, St. Michael's Hospital, Southwell Street, Bristol BS2 8EG, UK \\ d Department of Paediatric Neurology, Royal Manchester Children's Hospital, Oxford Road, Manchester M13 9WL, UK \\ ${ }^{\mathrm{e}}$ North West Thames Regional Genetics Service, Kennedy-Galton Centre, Northwick Park Hospital, Watford Road, Harrow HA1 3UJ, UK \\ ${ }^{\mathrm{f}}$ Department of Paediatric Neurology, John Radcliffe Hospital, Oxford OX3 9DU, UK \\ ${ }^{\mathrm{g}}$ Department of Paediatrics, Cheltenham General Hospital, Gloucestershire GL53 7AN, UK \\ ${ }^{\mathrm{h}}$ Department of Medical and Molecular Genetics, University of Birmingham School of Medicine, Institute of Biomedical Research, Birmingham B15 2TT, UK \\ ${ }^{i}$ Department of Paediatric Neurology, Birmingham Children's Hospital, Steelhouse Lane, Birmingham B4 6NH, UK
}

\section{A R T I C L E I N F O}

\section{Article history:}

Received 19 December 2009

Received in revised form 10 February 2010

Accepted 10 February 2010

Available online 16 February 2010

\section{Keywords:}

PLA2G6

PLAN

Duplication

Deletion

MLPA

ARMD

\begin{abstract}
A B S T R A C T
Phospholipase associated neurodegeneration (PLAN) comprises a heterogeneous group of autosomal recessive neurological disorders caused by mutations in the PLA2G6 gene. Direct gene sequencing detects $\sim 85 \%$ mutations in infantile neuroaxonal dystrophy. We report the novel use of multiplex ligationdependent probe amplification (MLPA) analysis to detect novel PLA2G6 duplications and deletions. The identification of such copy number variants (CNVs) expands the PLAN mutation spectrum and may account for up to $12.5 \%$ of PLA2G6 mutations. MLPA should thus be employed to detect CNVs of PLA2G6 in patients who show clinical features of PLAN but in whom both disease-causing mutations cannot be identified on routine sequencing.
\end{abstract}

(c) 2010 Elsevier Inc. All rights reserved.

\section{Introduction}

Autosomal recessive neurodegeneration associated with genetic defects in the PLA2G6 gene [1] may present with a number of phenotypes [2] including presentation in infancy [3,4] (infantile neuroaxonal dystrophy, INAD, MIM256600), childhood (atypical neuroaxonal dystrophy, neurodegeneration with brain iron accumulation, NBIA MIM610217, Karak syndrome MIM608395) [4,5] and also in adulthood [6,7] (early-onset dystonia-parkinsonism MIM612953). Mutation detection rate is particularly high (80-

\footnotetext{
* Corresponding author. Address: 2nd Floor Norton Court, Birmingham Women's Hospital, Metchley Park Road, Edgbaston, Birmingham B15 2TG, UK.

E-mail addresses: manju_dave@hotmail.com, m.kurian@bham.ac.uk (M.A. Kurian).
}

90\%) in children with classical clinical and radiological features of infantile PLAN $[2,8]$. $^{1}$

Classical INAD (infantile onset PLAN) accounts for the majority of cases, and is characterised by infantile onset truncal hypotonia and progressive psychomotor regression [3,4]. Over time, children develop bulbar dysfunction, pyramidal tract signs, optic atrophy, cerebellar features and extrapyramidal features [3,4,9-12]. MRI features can aid diagnosis [13-15]. The majority of patients have features of cerebellar atrophy [4]. Cerebellar gliosis is seen in the majority [4] but not all patients have this feature [16]. Some also have evidence of brain iron accumulation [3,4]. Generalised seizures are often reported [17-19]. Dysmorphia is rarely described [20]. Death usually occurs around the first decade [3,4].

\footnotetext{
${ }^{1}$ Abbreviations used: PLAN, phospholipase associated neurodegeneration; MLPA, multiplex ligation-dependent probe amplification; ARMD, Alu recombination-mediated deletion.
} 
Not all patients with typical clinical features of infantile PLAN have mutations in the PLA2G6 gene [4]. Possible explanations for this include genetic heterogeneity [1], PLA2G6 defects within intronic sequence or regulatory regions and CNVs that are undetected by standard diagnostic mutational screening strategies [21]. In recent years, MLPA has emerged as a high resolution technique to determine relative DNA sequence dosage [22,23].

We describe four children with infantile PLAN referred for diagnostic PLA2G6 screening in which both disease-causing mutations were not identified on direct gene sequencing. Further investigation with MLPA analysis detected a novel heterozygous duplication in patient 1 and a novel homozygous deletion in patients 2-4.

\section{Subjects and methods}

\section{Patients}

The patients described were referred to the West Midlands Regional Genetic Service for PLA2G6 analysis by their local paediatric neurologist/geneticist. The medical case notes were analysed to delineate the clinical features on history and examination. MRI brain scans for patient 1 were reviewed independently by 2 paediatric neuroradiologists (with consensus agreement on disparities).

\section{Molecular genetic investigation}

Techniques for DNA/RNA extraction, PLA2G6 sequencing, MLPA analysis and molecular characterisation of the CNVs are outlined in Supplementary data 1 .

\section{Results}

\section{Clinical cases}

\section{Patient 1}

Patient 1 was the first child of non-consanguineous healthy Caucasian parents. Early neurodevelopmental milestones were achieved. At 15 months, he developed gait instability and an alternating strabismus. Psychomotor regression ensued and by 1920 months of age, there was loss of ambulation. Between 2 and 3 years he developed 4 -limb spasticity. Speech regression was also evident. He developed severe bulbar dysfunction with excessive drooling and feeding difficulties requiring PEG feeding. Dystonia of all 4 -limbs was also evident by age 5 years. He did not have any seizures.

On clinical examination (age 5 years) he was not dysmorphic or microcephalic, but had evidence of a right-sided manifest squint and bilateral horizontal nystagmus. There was excessive drooling and tongue fasciculation. On neurological assessment he was found to have marked axial hypotonia. There was a postural kyphotic curvature of the spine. Limb examination revealed symmetrical 4-limb hypertonicity and hyperreflexia but no contractures. Plantar reflexes were upgoing bilaterally.

MRI brain examination was undertaken at age 2 and 2.9 years (Fig. 1). Initial MRI scan showed evidence of a hypoplastic cerebellum and vermis (Fig. 1A and B). There was no evidence of optic nerve hypoplasia or white matter abnormalities. On repeat MR neuroimaging at age 2.9 years, there was progressive cerebellar atrophy (Fig. 1C and D). Although minimal basal ganglia abnormalities were noted on initial imaging (Fig. 1E), mild iron accumulation within the basal ganglia was evident on repeat imaging (Fig. 1F). Electromyographic (EMG) signs of chronic denervation were evident in the upper limbs, lower limbs and bulbar musculature. Nerve conduction studies were normal. On EEG, widespread high amplitude fast activity at $16-22 \mathrm{~Hz}$ was seen. Visual evoked potentials (VEP) and electroretinogram (ERG) was normal at age 2 years. Ophthalmological review detected bilateral temporal disc pallor. Histological examination of nerve tissue from a rectal biopsy (age 2 years) was normal.

\section{Patient 2}

Patient 2, a 4 year old girl was born to healthy consanguineous (2nd cousin) Irish parents. All early developmental milestones were appropriately achieved. Symptom onset at 9-10 months of age commenced with psychomotor regression. She stopped vocalising, developed complete loss of ambulation and could only sit for brief periods with extensive support. There was no evidence of seizures.

On clinical examination, at age 21 months, she was not dysmorphic or microcephalic. There was evidence of marked axial hypotonia and upper and lower limb spasticity (but no contractures or spinal deformity). She had evidence of nystagmus on clinical examination. Ophthalmological examination did not detect any abnormalities.

MRI brain (age 18 months) revealed cerebellar atrophy and a marginally narrow pons but no evidence of basal ganglia abnormalities. Electromyogram abnormalities were similar to patient 1 . She did not have any other electrophysiological investigations (VER, ERG, EEG) or a sural/skin biopsy as repeated non-attendance at clinic appointments precluded further neurological investigation.

\section{Patients 3 and 4}

Patients 3 and 4, dizygotic male twins were born to healthy consanguineous (1st cousin) parents, of Irish origin. There was no family history of neurological disorders and the family were not known to be related to patient 2's kindred. The twins were born at 33 weeks gestation, but despite their prematurity, the postnatal course was uneventful. Early developmental milestones were appropriately achieved, but concerns were raised at 11 months of age as both children were yet to sit independently. At this stage both children were noted to have strabismus. Psychomotor regression ensued in both children with a gradual but progressive loss of cognitive and motor skills. A rapid decline in motor function was seen in patient 3 subsequent to a febrile viral illness at age 22 months. Following this illness, he developed infantile spasms associated with a hypsarrhythmic EEG pattern. At age 26 months, patient 4 also developed seizures (generalised tonic clonic episodes) with an EEG pattern of high voltage slow background with sharp and slow wave discharges seen independently in each temporal region. Repeat EEG (5 months later) showed mild excess of moderate voltage irregular slow activity with runs of high amplitude irregular delta activity with ill defined sharp components independently over both temporal regions. Both children had ophthalmological assessments showing optic atrophy. Over time, both children developed profound axial hypotonia, pyramidal tract features and bulbar dysfunction.

MRI brain (at 24 months of age in both children) revealed moderate cerebellar atrophy, but no cerebellar gliosis or brain iron accumulation. Electrophysiological investigation revealed absent sensory nerve action potentials associated with a myopathic pattern on EMG. No clear binocular pattern of vision was evident on VEP. A sural/skin biopsy was not undertaken in either patient.

\section{Molecular genetic investigation}

\section{Direct sequencing of PLA2G6}

Patient 1: A heterozygous mutation (c.1674delG; p.Leu560Trpf sX5) was detected in exon 12 (Supplementary Fig. 1). A 2nd mutation was not detected.

Patient 2-4: Molecular analysis did not detect any mutations in exons $1-4$ and $7-17$ of the PLA2G6 gene. Repeated failed attempts 
A

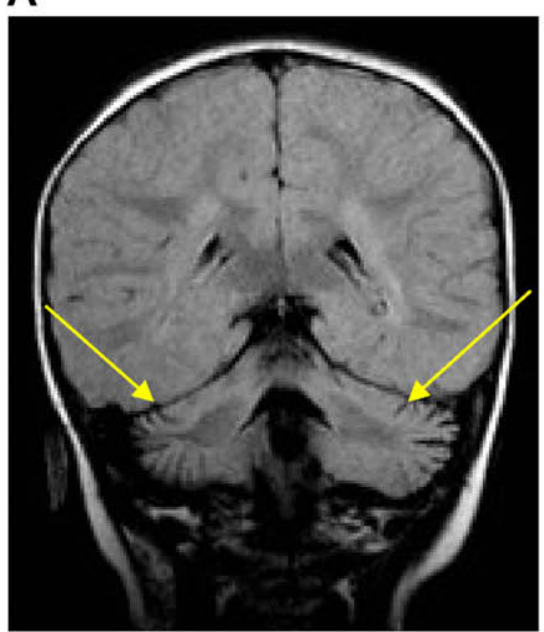

D

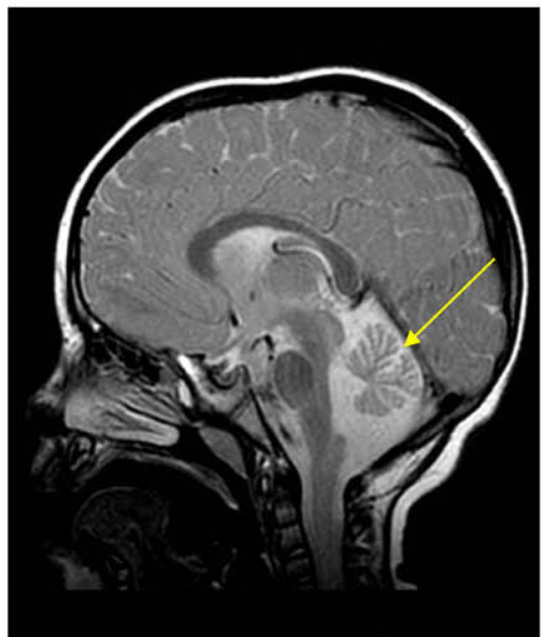

B

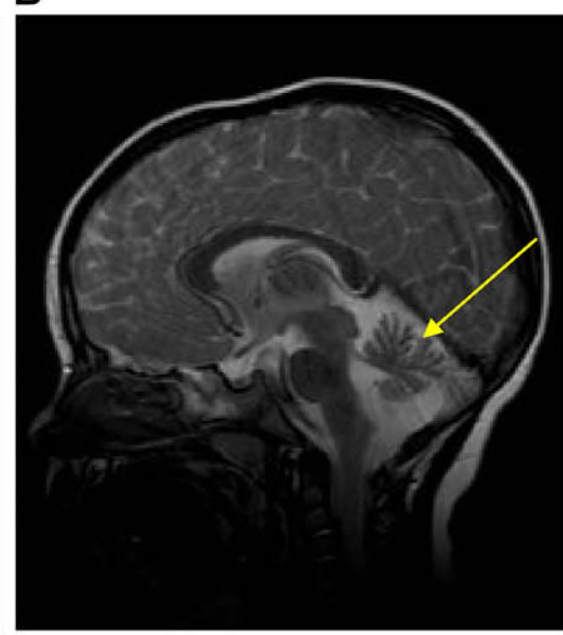

E

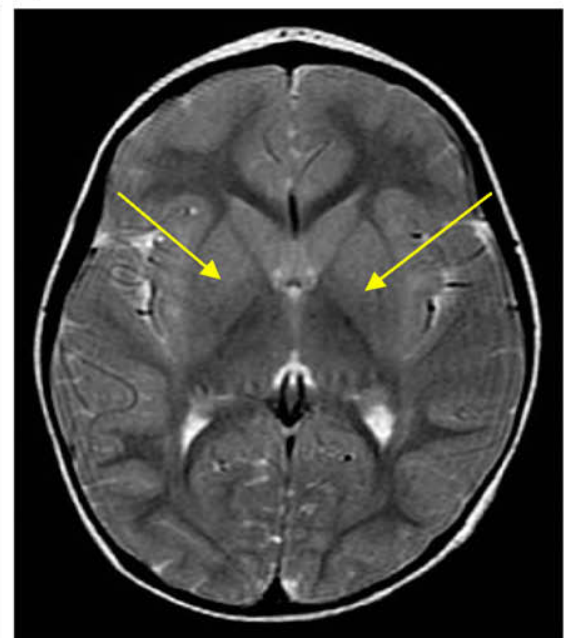

C

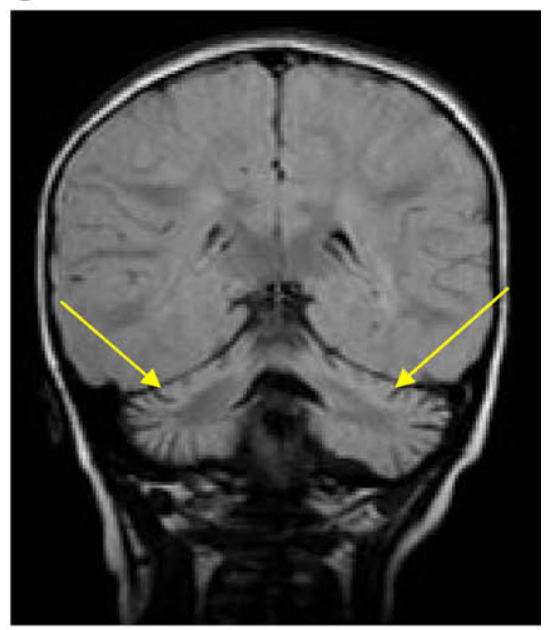

$\mathbf{F}$

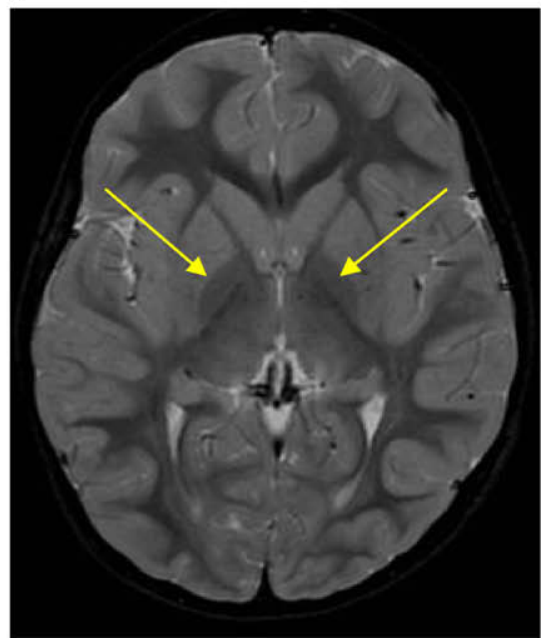

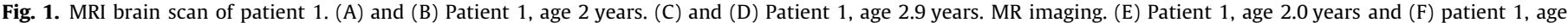

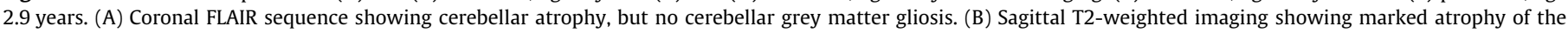

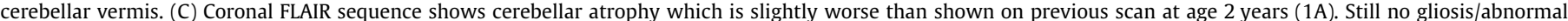

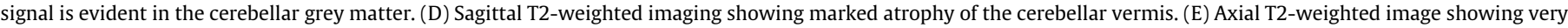

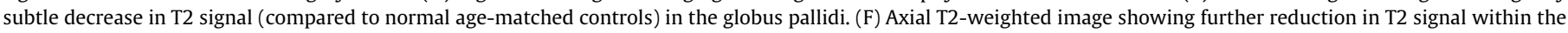
globus pallidi.

to amplify exons 5 and 6 (due to polymerase chain reaction failure, Supplementary Fig. 2) raised the possibility of an intragenic homozygous deletion.

\section{MLPA analysis}

Patient 1: A heterozygous duplication of exons 4, 5, 6 and 7 was identified (Supplementary Fig. 3).

Patient 2-4: A homozygous deletion of exons 5 and 6 was detected in all patients (Supplementary Fig. 4).

\section{Molecular genetic characterisation of the CNVS}

Patient 1: Fig. 2A-D. Primers were designed for cDNA amplification of a putative tandem duplication from exon 7 to exon 4 . Subsequent sequencing of patient 1 confirmed that the exon 4 , 5, 6 and 7 duplication occurred within the PLA2G6 gene leading to a pathogenic truncating mutation (r.426-?_1077-?dup p.Lys360LeufsX22).

Patient 2-4: Fig. 2E-G. PCR primers were designed to amplify the region between intron 4 and intron 6 . The PCR amplification products were observed for patients but not in control samples.
The genomic breakpoints were identified (g.40638_47282del6632, p.Leu204_Glu298del95) in intron 4 (between 38537112 and 38 $537123 \mathrm{bp}$ ) and in intron 6 (between 38530480 and 38530 $491 \mathrm{bp}$ ). The breakpoints could not be further delineated as there is a 12 bp region with $100 \%$ homology common to both intron 4 and intron 6 .

\section{Discussion}

To date, 75 different genetic alterations of PLA2G6 have been reported in PLAN $[1-4,6,8,12,17]$ including missense mutations ( $\sim 68 \%)$, insertions $(\sim 0.75 \%)$, deletions $(\sim 14 \%)$, nonsense mutations ( $\sim 14 \%$ ) and splice site mutations $(\sim 0.75 \%)$. We report the use of MLPA in the detection of previously undetected novel large intragenic PLA2G6 rearrangements in four patients with classical infantile PLAN. Although this only a recently reported diagnostic use of MLPA in PLA2G6 analysis [21], this diagnostic tool has already been successfully used in a number of other conditions [22,23] Indeed, MLPA analysis of the SCN1A gene in mutation-negative patients with Dravet's syndrome detected a significant chromosomal rear- 
A ACGTGAACAGCACCAGCTCCGCGGGAACACGGCCCTGCACGTGGCGGTGATGCGCAACCGCTTCGAC TGTGCCATAGTGCTGCTGACCCACGGGGCAAACGGGATGCCCGCGGAGAGCACGGCAACACCCCGCT GCACCTGGCCATGTCGCTGTGCCAATTGCGCGGAGAACGAGGAGGGCTGCACACCCCTGCACCTGGCC TGCCGCAAGGGTGATGGGGAGATCCTGGTGGAGCTGGTGCAGTACTGCCACACTCAGATGGATGTCAC CGACTACAAGGGAGAGACCGTCTTIC

B
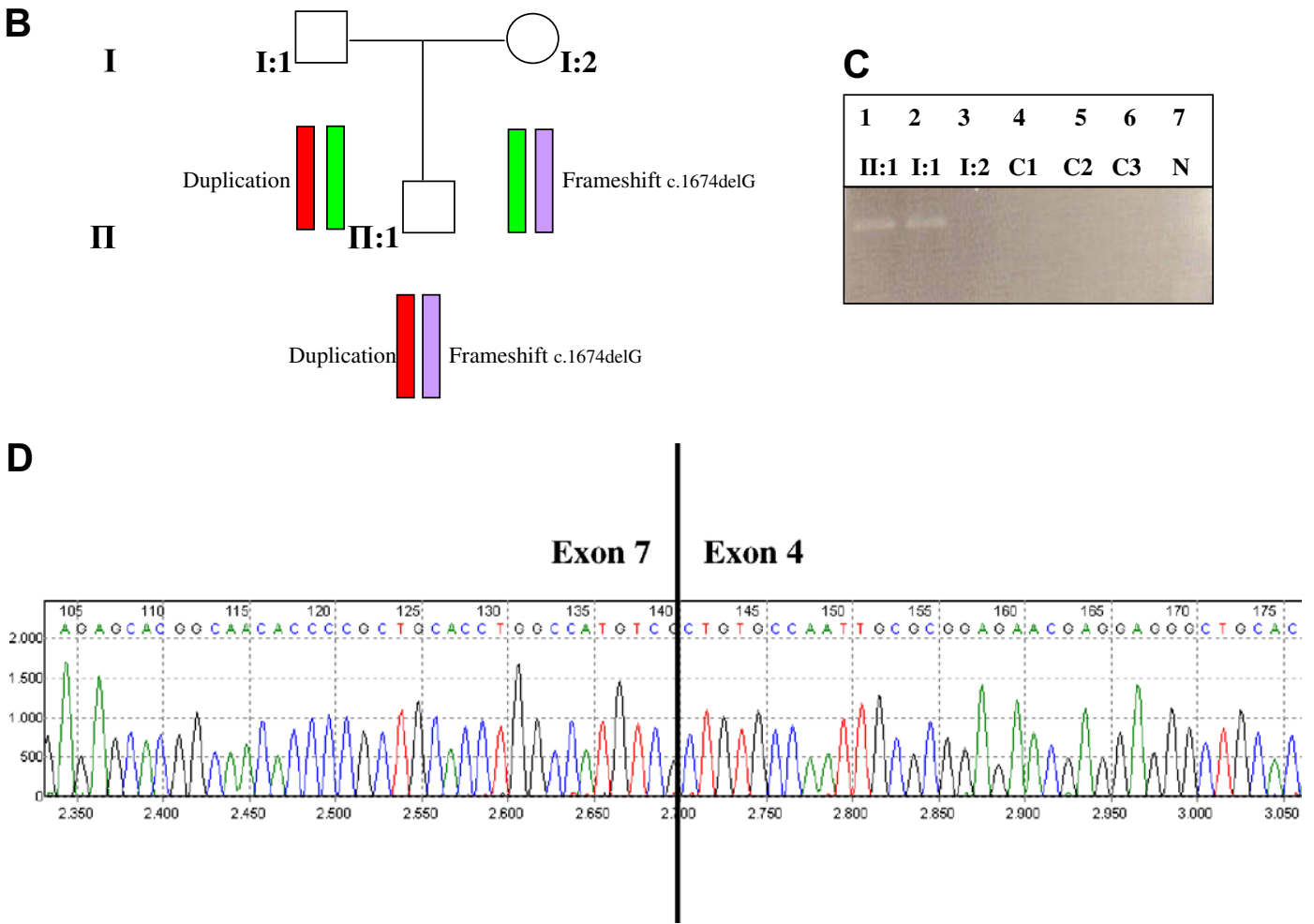

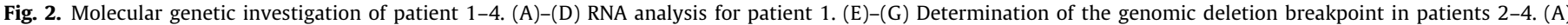

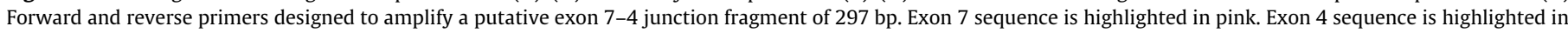

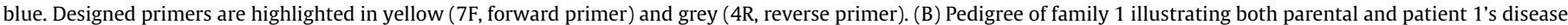

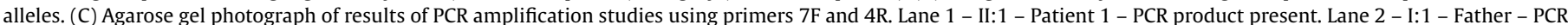

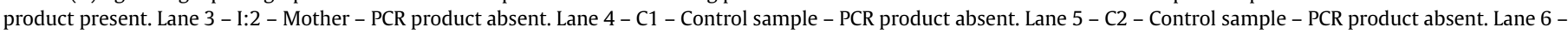

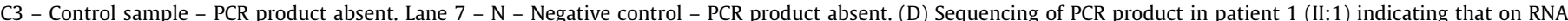

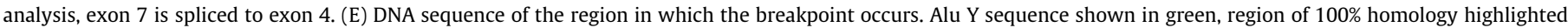

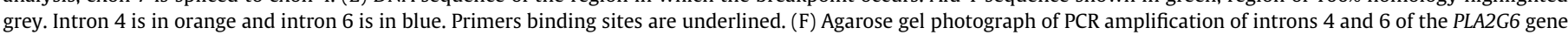

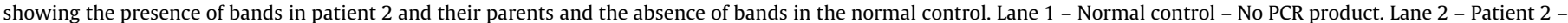

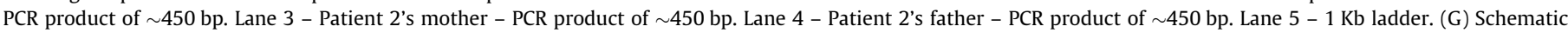

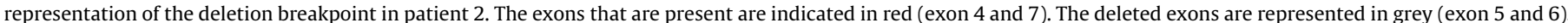

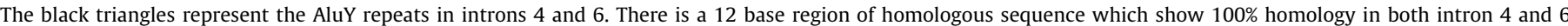
(shaded yellow box). (For interpretation of the references in colour in this figure legend, the reader is referred to the web version of this article.)

rangement rate of $12.5 \%$ [24,25]. From this study, we estimate that CNVs may also account for $12.5 \%$ PLA2G6 mutations identified in the UK Diagnostic Screening Service.

MLPA analysis has important diagnostic implications. In patient 1 , the heterozygous duplication could not be detected by standard direct gene sequencing. In patient 2 , failed attempts to amplify exons 5 and 6 could have been due to a number of reasons (failed PCR amplification or the presence of rare SNP variants in primer binding regions). However MLPA alone cannot provide an insight as to the precise genomic location and/or potential functional outcomes of the deletion/duplication [26]. Subsequent molecular characterisation has provided important information regarding the nature of these CNVs. In case 1 , analysis of cDNA revealed expression of mutant mRNA species containing a tandem duplication of exon 4, 5, 6, and 7, resulting in a frameshift and premature stop codon. In case 2 , genomic delineation of the centromeric and telomeric breakpoints revealed that both breakpoints were within an AluY repeat sequence (http://www.repeatmasker.org/) in intron 4 and intron 6 (showing 94\% overall homology) (www.blast.nc- bi.nlm.nih.gov). An Alu recombination-mediated deletion (ARMD) as a result of misalignment of the Alu Y repeats is thus the most likely mechanism for generating this deletion. Deletion of exons 5 and 6 is predicted to lead to an inframe deletion which results in partial loss of the seven ankyrin repeats of the PLA2G6 protein. Ankyrin repeats mediate protein-protein interactions and loss or disruption of this motif would be predicted to have a deleterious effect on normal iPLA 2 -VI function.

\section{Conclusion}

In conclusion, we describe the first reported use of MLPA in PLA2G6 analysis. Our data suggests that CNVs also have a role in the pathogenesis of PLAN. As part of a PLA2G6 diagnostic screening service, MLPA may contribute towards providing a definitive diagnosis in an affected individual. It may also help remove the need for unnecessary neurological investigation, improve the quality of genetic counselling and aid accurate prenatal diagnoses. It can 


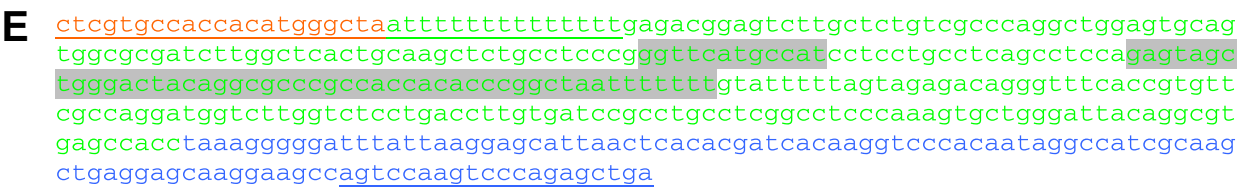

$\mathbf{F}$
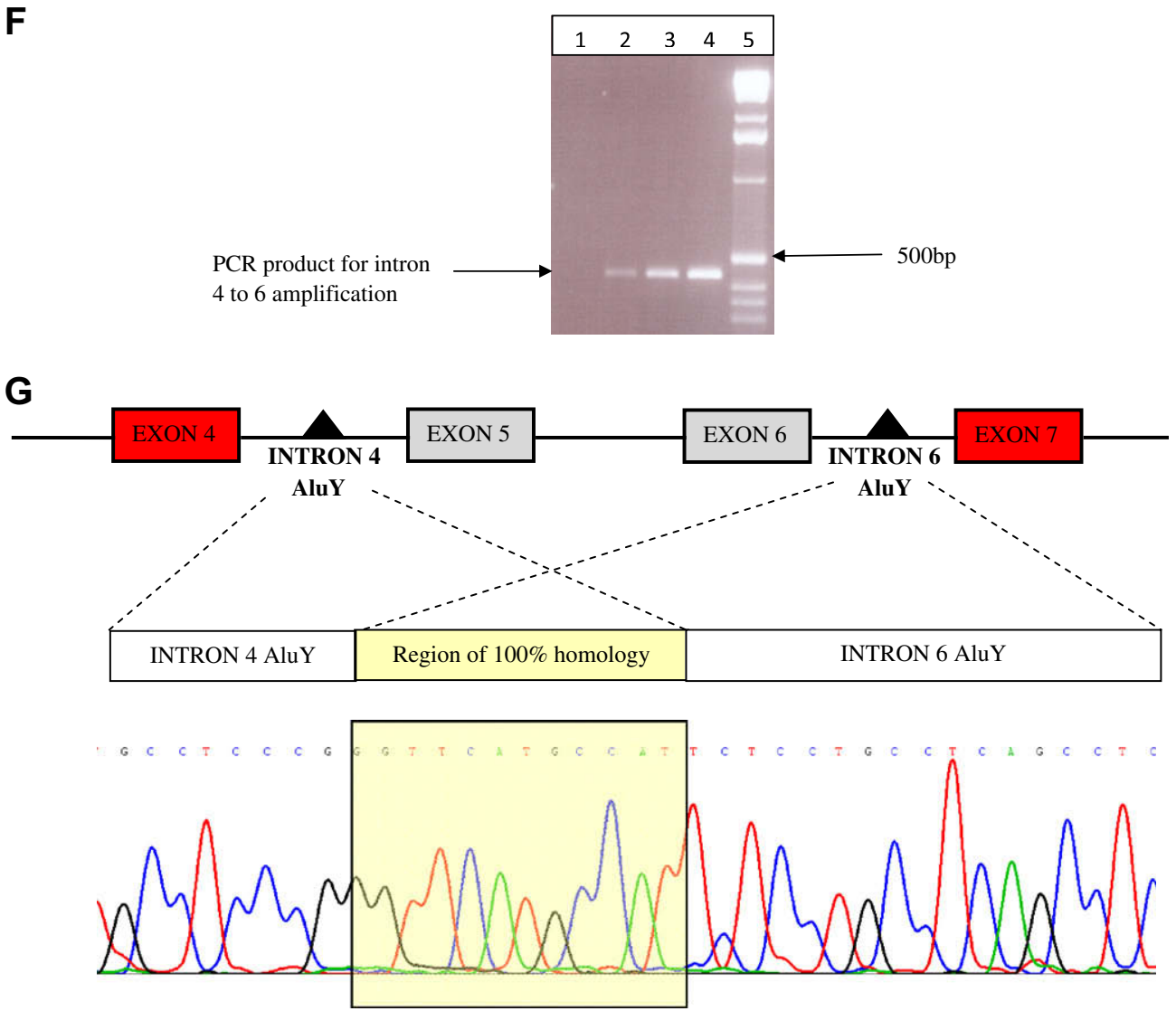

Fig. 2 (continued)

provide greater understanding of disease genotype-phenotype correlation as well as insights into sequence-related chromosomal breakpoints, recombination hotspots and disease mechanisms. Our observations thus have implications for molecular diagnosis and highlight the importance of MLPA as a second-line diagnostic tool and adjunct to direct sequencing in PLA2G6 screening.

\section{Acknowledgments}

We thank Birmingham Children's Hospital Research Foundation, BDF NewLife and Action Medical Research for financial support. We also thank the sequencing team at the West Midlands Regional Genetics Laboratory at Birmingham Women's NHS Foundation Trust.

\section{Appendix A. Supplementary data}

Supplementary data associated with this article can be found, in the online version, at doi:10.1016/j.ymgme.2010.02.009.

\section{References}

[1] N.V. Morgan, S.K. Westaway, J.E. Morton, A. Gregory, P. Gissen, S. Sonek, H Cangul, J. Coryell, N. Canham, N. Nardocci, G. Zorzi, S. Pasha, D. Rodriguez, I. Desguerre, A. Mubaidin, E. Bertini, R.C. Trembath, A. Simonati, C. Schanen, C.A. Johnson, B. Levinson, C.G. Woods, B. Wilmot, P. Kramer, J. Gitschier, E.R. Maher, S.J. Hayflick, PLA2G6, encoding a phospholipase A2, is mutated in neurodegenerative disorders with high brain iron, Nat. Genet. 38 (2006) $752-754$

[2] A. Gregory, B.J. Polster, S.J. Hayflick, Clinical and genetic delineation of neurodegeneration with brain iron accumulation, J. Med. Genet. 46 (2009) 73-80.

[3] M.A. Kurian, N.V. Morgan, L. MacPherson, K. Foster, D. Peake, R. Gupta, S.G. Philip, C. Hendriksz, J.E. Morton, H.M. Kingston, E.M. Rosser, E. Wassmer, P. Gissen, E.R. Maher, Phenotypic spectrum of neurodegeneration associated with mutations in the PLA2G6 gene (PLAN), Neurology 70 (2008) 16231629 .

[4] S.K. Westaway, I.E. Holm, P.T. Kotzbauer, P. Hogarth, S. Sonek, J.C. Coryell, T.M. Nguyen, N. Nardocci, G. Zorzi, D. Rodriguez, I. Desguerre, E. Bertini, A. Simonati, B. Levinson, C. Dias, C. Barbot, I. Carrilho, M. Santos, I. Malik, J. Gitschier, S.J. Hayflick, Neurodegeneration associated with genetic defects in phospholipase A(2), Neurology 71 (2008) 1402-1409.

[5] A. Mubaidin, E. Roberts, D. Hampshire, M. Dehyyat, A. Shurbaji, M. Mubaidien, A. Jamil, A. Al-Din, A. Kurdi, C.G. Woods, Karak syndrome: a novel degenerative disorder of the basal ganglia and cerebellum, J. Med. Genet. 40 (2003) 543546.

[6] C. Paisan-Ruiz, K.P. Bhatia, A. Li, D. Hernandez, M. Davis, N.W. Wood, J. Hardy, H. Houlden, A. Singleton, S.A. Schneider, Characterization of PLA2G6 as a locus for dystonia-parkinsonism, Ann. Neurol. 65 (2009) 19-23.

[7] F. Sina, S. Shojaee, E. Elahi, C. Paisán-Ruiz, R632W mutation in PLA2G6 segregates with dystonia-parkinsonism in a consanguineous Iranian family, Eur. J. Neurol. 16 (2009) 1-4.

[8] M.A. Kurian, D. Crompton, P. Rehal, N.V. Morgan, P. Gissen, F. Macdonald, E.R. Maher, Evaluation of the diagnostic screening service for PLA2G6 mutations in phospholipase associated neurodegeneration (PLAN), Dev. Med. Child Neurol. 51 (2009) 16.

[9] J. Aicardi, P. Castelein, Infantile neuroaxonal dystrophy, Brain 102 (1979) 727748.

[10] N. Nardocci, G. Zorzi, L. Farina, S. Binelli, W. Scaioli, C. Ciano, L. Verga, L. Angelini, M. Savoiardo, O. Bugiani, Infantile neuroaxonal dystrophy: clinical spectrum and diagnostic criteria, Neurology 52 (1999) 1472-1478. 
[11] L. Farina, N. Nardocci, M.G. Bruzzone, L. D’Incerti, G. Zorzi, L. Verga, M. Morbin, M. Savoiardo, Infantile neuroaxonal dystrophy: neuroradiological studies in 11 patients, Neuroradiology 41 (1999) 376-380.

[12] I. Carrilho, M. Santos, A. Guimarães, J. Teixeira, R. Chorão, M. Martins, C. Dias, A. Gregory, S. Westaway, T. Nguyen, S. Hayflick, C. Barbot, Infantile neuroaxonal dystrophy: what's most important for the diagnosis?, Eur J. Paediatr. Neurol. 12 (2008) 491-500.

[13] L. Farina, N. Nardocci, M.G. Bruzzone, L. D'Incerti, G. Zorzi, L. Verga, M. Morbin, M. Savoiardo, Infantile neuroaxonal dystrophy: neuroradiological studies in 11 patients, Neuroradiology 41 (1999) 376-380.

[14] Y. Tanabe, M. Iai, M. Ishii, et al., The use of magnetic resonance imaging in diagnosing infantile neuroaxonal dystrophy, Neurology 43 (1993) 110113.

[15] A. McNeill, D. Birchall, S.J. Hayflick, A Gregory, J.F. Schenk, E.A. Zimmerman, H. Shang, H. Miyajima, P.F. Chinnery, T2 and FSE MRI distinguishes four subtypes of neurodegeneration with brain iron accumulation, Neurology 70 (2008) 1614-1619.

[16] R. Biancheri, A. Rossi, G. Alpigiani, M. Filocamo, C. Gandolfo, R. Lorini, C. Minetti, Cerebellar atrophy without cerebellar cortex hyperintensity in infantile neuroaxonal dystrophy (INAD) due to PLA2G6 mutation, Eur. J. Paediatr. Neurol. 11 (2007) 175-177.

[17] Y. Wu, Y. Jiang, Z. Gao, J. Wang, Y. Yuan, H. Xiong, X. Chang, X. Bao, Y. Zhang, J. Xiao, X. Wu, Clinical study and PLA2G6 mutation screening analysis in Chinese patients with infantile neuroaxonal dystrophy, Eur. J. Neurol. 16 (2009) 240245.

[18] B.W Scheithauer, L.S. Forno, L.J. Dorfman, C.A. Kane, Neuroaxonal dystrophy (Seitelberger's disease) with late onset, protracted course and myoclonic epilepsy, J. Neurol. Sci. 36 (1978) 247-258.
19] F. Barontini, M. Papini, Late infantile neuroaxonal dystrophy. An unusual case with predominantly myoclonic-epileptic symptomatology, Riv. Patol. Nerv. Ment. 101 (1981) 171-184.

[20] M. Seven, A. Ozkilic, A. Yuksel, Dysmorphic face in two siblings with infantile neuroaxonal dystrophy, Genet. Couns. 13 (2002) 465-473.

[21] E.V. Haverfield, M.A. Dempsey, A. Gregory, S.K. Westaway, S.J. Hayflick, S. Das Intragenic deletion and duplication analysis of the PANK2 and PLA2G6 genes in patients with NBIA, ACMG Annual Meeting, Phoenix, AZ, 2008.

[22] J.P. Schouten, C.J. McElgunn, R. Waaijer, D. Zwijnenburg, F. Diepvens, G. Pals, Relative quantification of 40 nucleic acid sequences by multiplex ligationdependent probe amplification, Nucleic Acids Res. 30 (2002) e57.

[23] P. Kozlowski, A.J. Jasinska, D.J. Kwiatkowski, New applications and developments in the use of multiplex ligation-dependent probe amplification, Electrophoresis 29 (2008) 4627-4636.

[24] C. Depienne, O. Trouillard, C. Saint-Martin, I. Gourfinkel-An, D. Bouteiller, W. Carpentier, B. Keren, B. Abert, A. Gautier, S. Baulac, A. Arzimanoglou, C. Cazeneuve, R. Nabbout, E. LeGuern, Spectrum of SCN1A gene mutations associated with Dravet syndrome: analysis of 333 patients, J. Med. Genet. 46 (2009) 183-191.

[25] C. Marini, I.E. Scheffer, R. Nabbout, D. Mei, K. Cox, L.M. Dibbens, J.M. McMahon, X. Iona, R.S. Carpintero, M. Elia, M.R. Cilio, N. Specchio, L. Giordano, P. Striano, E. Gennaro, J.H. Cross, S. Kivity, M.Y. Neufeld, Z. Afawi, E. Andermann, D. Keene, O. Dulac, F. Zara, S.F. Berkovic, R. Guerrini, J.C. Mulley, SCN1A duplications and deletions detected in Dravet syndrome: implications for molecular diagnosis, Epilepsia 11 (2009) 1670-1678.

[26] A. McCart, A Latchford, E. Volikos, A. Rowan, I. Tomlinson, A Silver, A novel exon duplication event leading to a truncating germ-line mutation of the APC gene in a familial adenomatous polyposis family, Fam. Cancer 5 (2006) 205-208. 